\title{
U-Mo Monolithic Fuel for Nuclear Research and Test Reactors
}

\author{
RAMPRASHAD PRABHAKARAN ${ }^{1,2}$ \\ 1.-Pacific Northwest National Laboratory, Richland, WA, USA. 2.-e-mail: \\ ramprashad.prabhakaran@pnnl.gov
}

Research and test reactors consist of a wide range of civil and commercial nuclear reactors that are generally not used for power generation. The primary purpose of these reactors is to provide a neutron source for research and development purposes. These reactors are used for a number of applications, such as testing and analysis of materials, industrial processing and production of radioisotopes. In addition to the nuclear field, these reactors are also used in other areas, such as physics, chemistry, biology, geology, archeology, environmental science, and medicine. ${ }^{1,2}$

As per the International Atomic Energy Agency (IAEA) database dated April 2016, there are 243 operational research reactors, 7 under construction, 11 being planned, 134 reactors have been permanently shut down and 352 reactors have been decommissioned. About half of the operational research reactors are over 40 years old. ${ }^{3}$ The U.S. Nuclear Regulatory Commission (NRC) regulates 42 research and test reactors of which 31 are currently operating. Most research and test reactors are at universities or colleges in the United States. ${ }^{2}$

Research and test reactors are smaller in size and operate at lower temperature (typical coolant temperature is below $100^{\circ} \mathrm{C}$ ) when compared to power reactors, but the operating conditions are more rigorous. The peak power density is about $5 \mathrm{~kW} / \mathrm{cc}$ for a typical power reactor, whereas it could be about $17 \mathrm{~kW} / \mathrm{cc}$ (in the fuel meat) for a typical research and test reactor. The burn-up is also very high in a research and test reactor. In a power reactor, burn-up is limited to less the $10 \%$ of the heavy metal while many research reactors will see complete depletion of heavy metal in peak locations. ${ }^{4}$ The power of a typical power reactor is about $3000 \mathrm{MWt}$ (sufficient to power about 200,000 households in the peak summer), whereas it is only in the range of $0.10 \mathrm{~W}$ (sufficient to power a night lamp)

Ramprashad Prabhakaran is the JOM advisor for the Nuclear Materials Committee of the TMS Structural Materials Division, and guest editor for the topic U-Mo Monolithic Fuel for Nuclear Research and Test Reactors in this issue. and $20 \mathrm{MWt}$ (sufficient to power about 20 standard medical x-ray machines) for a typical research and test reactor. ${ }^{2}$ These reactors are also covered by IAEA safety inspections and safeguards, similar to power reactors. These reactors employ a wider range of designs when compared to power reactors. ${ }^{5}$ About $80 \%$ of the world's power plants are classified into two basic types (pressurized water reactors and boiling water reactors). ${ }^{3}$

The first research and test reactors built around the 1940s which employed LEU (low enriched uranium: < 20 wt.\% U-235) fuel were low-powered reactors, used mainly for studying reactor physics and reactor technology. However, due to the increased use of these reactors for a number of applications, the demand for higher specific power and the need to use greater U-235 concentrations increased, thus leading to the use of HEU (high enriched uranium: > 20 wt.\% U-235; typically, $90 \%$ enriched) fuel, instead of LEU fuel. ${ }^{4}$

The Reduced Enrichment for Research and Test Reactors (RERTR) Program was initiated by the United States Department of Energy in August 1978, in response to the increased concern about the potential diversion of HEU for use in nuclear weapons. ${ }^{4,6}$ Since the $1980 \mathrm{~s}$, the United States policy has encouraged the use of LEU fuels for all new research and test reactor designs worldwide, and also for the conversion of the existing reactors from the HEU to LEU fuel. ${ }^{7}$

The RERTR program (now called the Reactor Conversion Program under the National Nuclear Security Administration's Office of Material Management and Minimization) identified 106 research and test reactors in the United States and overseas for conversion to LEU fuel. ${ }^{8}$ Eighty-seven of the targeted 106 research and test reactors have been or can be converted from the HEU to LEU fuel, using the RERTR qualified dispersion fuels (fuel consists of fuel kernels surrounded by aluminum matrix material; density: $\left.8 \mathrm{~g} / \mathrm{cm}^{3}\right) .{ }^{9}$ The remaining 19 reactors have an exotic geometry and/or are highpower/high-flux reactors. A majority of the 
remaining high-power research and test reactors still operating on HEU fuel have fissile atom density requirements that are too high for conversion to existing LEU fuel elements, i.e., dispersion fuels, since a decrease in uranium enrichment requires an increase in the uranium density $\left(>14.5 \mathrm{~g} / \mathrm{cm}^{3}\right)$ to maintain the net fissile atom density of the fuel. $^{5,10,11}$

This has led to a new pursuit of developing a high uranium density monolithic fuel that possesses the greatest possible uranium density in the fuel region. Based upon the density requirements and irradiation performance, metallic uranium alloy was chosen as a superior candidate for fuel materials. ${ }^{5}$ Uranium has some material drawbacks, such as poor oxidation and corrosion resistance, low hardness and yield strength, and lack of dimensional stability of the room-temperature alpha phase. Dimensional stability of the fuel during reactor operation is extremely important. ${ }^{12}$ Therefore, the high-temperature gamma $(\gamma)$ phase is desired, based on the isotropy that can be retained at room temperature and better resistance to thermal recycling and radiation damage. ${ }^{13}$ In order to stabilize the high-temperature $\gamma$ phase, an alloying element is added, such as molybdenum (Mo) that has a high solid solubility in bec $\gamma$ uranium. ${ }^{10}$ The U-Mo phase diagram shows that U-10Mo is near the eutectoid transformation of gamma-U and provides a good compromise between the amount of alloying metal needed for phase stability and the fuel density. ${ }^{14,15}$

The metallic fuel selected to replace the current HEU fuels is the LEU-10wt.\% Mo alloy in the form of a thin sheet or foil encapsulated in AA6061 aluminum alloy with a zirconium interlayer. ${ }^{12,16}$ The U-10Mo monolithic fuel can achieve the desired higher uranium density $\left(15.6 \mathrm{~g} / \mathrm{cm}^{3}\right)$. In order to effectively lead this investigation, new developments in processing and fabrication of the fuel elements have been initiated, along with a better understanding of material behavior before and after irradiation as a result of these new developments.

Complex materials processing techniques such as casting, thermal annealing, hot and cold rolling, coating, and hot isostatic pressing are being used to fabricate LEU-10Mo fuel plates. Hence, it is very important to obtain processing-structure-properties correlations. Efforts are ongoing to utilize computational modeling to understand these complex thermomechanical processes. The article written by $\mathrm{Xu}$ et al. describes the application of integrated computational materials engineering (ICME) concepts to integrate three individual modeling components (homogenization, microstructurebased finite element method for hot rolling, and carbide particle distribution) to simulate the early stage of LEU-10Mo alloy manufacturing processes.

As a part of LEU-10Mo monolithic fuel development, reactor experiments are being performed in the Advanced Test Reactor (Idaho Falls, ID, USA). To support fuel qualification, the fuel should exhibit mechanical integrity, geometric stability, and stable and predictable irradiation behavior at high powers and high fission densities. The article authored by Keiser et al. provides an overview of the microstructures observed at different regions of interest in fuel plates (fabricated using laboratoryscale methods) before and after irradiation for the fuel samples that have been tested. Discussions regarding observed microstructural changes during irradiation that may impact fuel performance are presented in this article.

Efforts are ongoing to perform irradiation testing of this new fuel system to support generic regulatory approval that will allow the fuel to be used in subsequent reactor licensing and conversion efforts. Post-irradiation non-destructive examination (such as visual, neutron radiography, profilometry, and precision gamma scanning) and subsequent analyses are used to demonstrate that the fuel meets established irradiation performance requirements for mechanical integrity, geometric stability, and stable and predictable behavior. The article written by Williams et al. presents the results of post-irradiation non-destructive examination performed on four curved full-size fuel plates (AFIP-7 experiment) which were irradiated under moderate operating conditions in the Advanced Test Reactor in order to evaluate the fuel performance for geometries that are prototypic of research reactor fuel assemblies.

Irradiation-induced recrystallization, a general phenomenon that has been observed in various nuclear fuels $\left(\mathrm{UO}_{2}, \mathrm{U}-\mathrm{Mo}\right.$ dispersion and monolithic fuels) can accelerate inter-granular gas bubble growth rates and swelling kinetics. The article authored by $\mathrm{Hu}$ et al. presents the results of a recently developed recrystallization model to study the effect of microstructures and radiation conditions on recrystallization kinetics in U-10Mo fuels. This model integrates the rate theory of intragranular gas bubbles and interstitial loop evolutions, and a phasefield model of recrystallization zone evolution.

The following articles are published under the topic "U-Mo Monolithic Fuel for Nuclear Research and Test Reactors" in the December 2017 issue (vol. 69 , no. 12) of $J O M$ and can be accessed via the $J O M$ page at http://ink.springer.com/journal/11837/69/ 12/page/1.

- "Process modeling early stages of U-10wt.\% molybdenum alloys using integrated computational materials engineering concepts" by Zhijie $\mathrm{Xu}$, Xiaowo Wang, Ayoub Soulami, Xiaohua $\mathrm{Hu}$, Curt Lavender, and Vineet Joshi.

- "Observed changes in as-fabricated U-10Mo monolithic fuel microstructures after irradiation in the Advanced Test Reactor" by Dennis Keiser, Jan-Fong Jue, Brandon Miller, Jian Gan, Adam Robinson, and James Madden.

- "Post-irradiation non-destructive analyses of the AFIP-7 experiment" by Walter Williams, Adam Robinson, and Barry Rabin. 
- "A rate-theory-phase-field model of irradiationinduced recrystallization in UMo nuclear fuels" by Shenyang Hu, Vineet Joshi, and Curt Lavender.

\section{REFERENCES}

1. C. West, Research reactors: an overview, CONF-970649-9, ANS Nuclear News, Oct 1997.

2. Backgrounder on Research and Test Reactors, Fact Sheets, The U.S. Nuclear Regulatory Commission, https://www. nrc.gov/reading-rm/doc-collections/fact-sheets/research-re actors-bg.html (updated August 2015).

3. Research Reactors, World Nuclear Association, http://www. world-nuclear.org/information-library/non-power-nuclearapplications/radioisotopes-research/research-reactors.aspx (updated April 2017).

4. D. Wachs, Reactor conversion, Nuclear Engineering International, Fuel and Fuel Cycle (2010).

5. S. Van Den Berghe, A. Leenaers, E. Koonen, and L. Sannen, Adv. Sci. Technol. 73, 78 (2010).
6. J. Snelgrove, G. Hofman, M. Meyer, C. Trybus, and T. Wiencek, Nucl. Eng. Des. 178, 119 (1997).

7. CFR50, Federal Register 51 (377), 1 (1986).

8. C. Landers, Reactors identified for conversion, Proceedings of the 27th International RERTR Meeting, 6-10 Nov, Boston, MA (2005).

9. D. Wachs, INL/EXT-05-01017, Rev. 3, Idaho National Laboratory, USA (2007).

10. A. Holden, Dispersion Fuel Elements (Philadelphia: Gordon and Breach Science, 1968).

11. M. Meyer, G. Hofman, S. Hayes, C. Clark, T. Wiencek, J. Snelgrove, R. Strain, and K. Kim, J. Nucl. Mater. 304, 221 (2002).

12. D. Burkes, R. Prabhakaran, J.-F. Jue, and F. Rice, Metall. Mater. Trans. A 40A, 1069 (2009).

13. J. Kittel, B. Frost, J. Mustelier, K. Bagley, G. Crittenden, and J. Van Dievoet, J. Nucl. Mater. 204, 1 (1993).

14. D. Wachs, C. Clark, and R. Dunavant, INL / EXT-08-13840 (USA: Idaho National Laboratory, 2008).

15. D. Senor and D. Burkes, PNNL-22528, Rev. 1, Pacific Northwest National Laboratory, USA (2014).

16. M. Meyer, J. Gan, J. Jue, D. Keiser, E. Perez, A. Robinson, D. Wachs, N. Woolstenhulme, G. Hofman, and Y. Kim, Nuclear. Eng. Technol. 46, 169 (2014). 